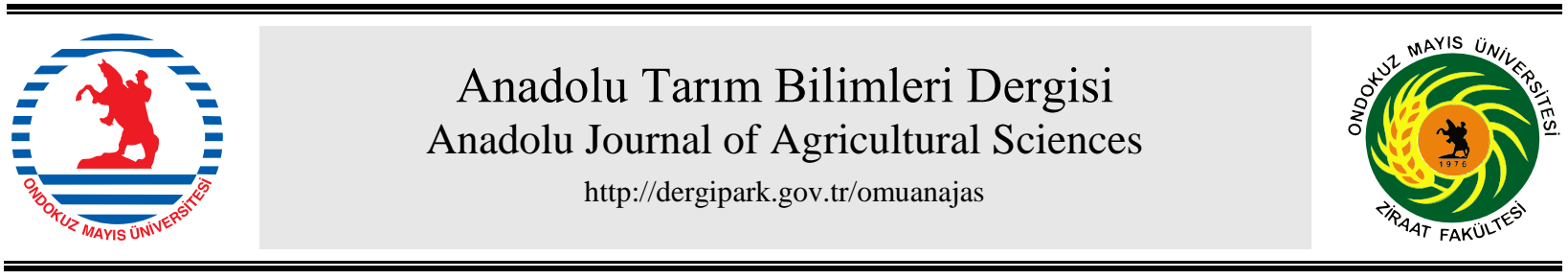

Araştırma/Research

Anadolu Tarım Bilim. Derg./Anadolu J Agr Sci, 33 (2018)

ISSN: 1308-8750 (Print) 1308-8769 (Online)

doi: 10.7161/omuanajas.371463

\title{
Faz değişimine bağlı olarak ısı iletkenliği denkleminin incelenmesi ve toprak neminin isısal yayınıma etkisi
}

\author{
Coşkun Gülser ${ }^{\mathrm{a}}$, İmanverdi Ekberli ${ }^{\mathrm{a}^{*}}$, Amrakh Mamedov $^{\mathrm{b}}$ Nutullah Özdemir $^{\mathrm{a}}$ \\ ${ }^{a}$ Ondokuz Mayls Üniversitesi Ziraat Fakültesi, Toprak Bilimi ve Bitki Besleme Bölümü, Atakum/Samsun \\ ${ }^{b}$ Arid Land Research Center, Faculty of Agriculture, Tottori University, Tottori, Japan \\ *Sorumlu yazar/corresponding author: iman@omu.edu.tr
}

Geliş/Received 26/12/2017

Kabul/Accepted 06/08/2018

\begin{abstract}
ÖZET
Isı iletkenlik denkleminin farklı toprak katmanlarına uygulanmasında, toprak sıcaklığındaki faz değişiminin dikkate alınması gerekir. Bu çalışmada, farklı toprak katmanları için 1sı iletkenlik denkleminin çözümünde faz değişimi dikkate alınarak, çözümün günlük toprak sıcaklık değişiminin tahmininde uygulanabilirliği gösterilmiştir. Toprağın 10,20 ve $50 \mathrm{~cm}$ derinliklerinde, 1sı iletkenlik denkleminin çözümü ile hesaplanan ve ölçülen sıcaklık değerleri arasındaki hata kareler ortalamasının karekökü, mutlak hata, maksimum nispi hata, ortalama yanılgı hatası, uygunluk indeksi ve modelin etkinliği hesaplanmıştır. İstatistiksel değerlendirmeler, 1s1 iletkenlik denkleminin faz değişimini içeren sınır koşulundaki çözümünün, toprak derinliği boyunca günlük sıcaklık değişiminin tahmininde kullanılabilirliğini göstermektedir. Toprağın ısısal yayınım katsayısı artan toprak nemine bağlı olarak azalan artış göstermekte, ısısal yayınım ve nem arasındaki ilişkinin ise parabolik fonksiyonla ifadesi mümkün gözükmektedir.
\end{abstract}

Investigating of heat conductivity equation with consideration of phase change and effect of soil moisture on heat diffusivity

\section{ABSTRACT}

Phase change in soil temperature should be taken into account in application of heat conductivity equation to different soil layers. In this study, applicability of the solution in daily soil temperature change was provided with consideration of phase change in the heat conductivity equation. Root mean square error, absolute error, maximum relative error, mean bias error, and conformity index between measured and estimated temperature values of the solution of heat conductivity equation, and efficiency of the model were calculated at 10,20 and $50 \mathrm{~cm}$ depths of soil. Results of statistical evaluations showed that solution of heat conductivity equation within the given boundary condition, including phase change, can be used for the prediction of daily temperature change along with soil depth. Soil heat diffusivity showed declining increase with increasing in soil moisture content, and the relationship between heat diffusivity and moisture can be expressed by the parabolic function.

Anahtar Sözcükler: Toprak sicaklığı Is1 iletkenlik denklemi Isisal yayınım $\mathrm{Nem}$

\section{Giriş}

Toprak sıcaklığının optimum düzeyde olması, toprak verimliliğinin artırılması, bitki gelişimi, ekim zamanının belirlenmesi vb. için önemlidir. Sürekli olarak atmosfer olayları etkisinde olan toprakta sıcaklığın değişimi, toprağın fiziksel, kimyasal ve biyolojik özelliklerine etki yapmaktadır. İklim koşullarının değişimine bağlı olarak, toprak yüzeyinde ve dolayısıyla aşağ 1 katmanlarında sıcaklığın değişimi farklılık göstermektedir. Toprak profili boyunca sicaklık değerlerinin farklı olması, toprakta 1Sı iletkenliğine neden olmaktadır. Sıcaklık dağılımının katmanlar için nicel olarak değerlendirilmesi toprağın 1S1 iletkenliği denklemi ile mümkün olabilmektedir.

Toprak sıcaklığı, arazi ile atmosfer arasındaki etkileşimlerin bir sonucu olarak ortaya çıkan önemli bir faktördür. Temel olarak, toprağın fiziksel süreçleri, atmosfer ile olan kitle alışverişinin hızlarını ve yönlerini belirler. Davidson ve Janssens (2006), Chen ve ark. (2013), Rafique ve ark. (2014) ve Yvon-Durocher ve ark. (2014), toprak sicaklığının toprağın 
biyojeokimyasal süreçlerine ve karbon dioksit salınımına da etki ettiğini göstermişlerdir. Toprakta sıcaklık değişiminin tahmini ve 1s1 iletiminin değerlendirilmesi, 1s1 iletkenliği denkleminin uygulanması ile mümkün olup, çeşitli araştırmalarda kullanılmıştır (Chacko ve Renuka, 2002; Elias ve ark., 2004; Gulser ve Ekberli 2004; Ekberli ve Sarılar, 2014; Lei ve ark., 2011; Liang, 2017; Knight ve ark., 2018). Chacko ve Renuka (2002), 1s1 iletkenlik modelini toprağın farklı derinliklerinde 36 saatlik sicaklık tahmininde kullanmışlardır.

Toprak yüzeyi ve derinliği boyunca toprak özelliklerinin değişiminin araştırılmasında, toprak sıcaklığının değerlendirilmesi önemlidir. Sicaklığın tahmini için modellerin kullanılmasında ise, toprağın diğer isısal parametreleri ile beraber isisal yayınım katsayısının belirlenmesi de gereklidir (Van Wijk, 1963; Farouki, 1981; Camillo ve ark., 1983; Novak ve Black, 1985; Milly, 1986; Passerat de Silans ve ark., 1989; Braud ve ark., 1995; Ekberli ve ark., 2015a; Ekberli ve Gülser, 2015; Ekberli ve Sarılar, 2015b). Isısal yayınım katsayısının belirlenmesinde teorik ve ampirik modellerden kullanılmaktadır (Lettau, 1954; de Vries, 1963; Johansen, 1975; Passerat de Silans ve ark., 1996). Isı iletkenliği ve 1sı yayınımı hacimsel ısı kapasitesi ile ilişkili olduğundan, yalnızca birinin belirlenmesi mümkündür. Isısal yayınım 1s1 iletimi sürecini daha iyi açıkladığından, genellikle isısal yayınımın belirlenmesi tercih edilmektedir.

Toprakların 1sısal özellikleri, dolayısıyla isısal yayınım katsayısı; deneysel, laboratuvar yöntemleri ile ve matematiksel modellerle belirlenebilmektedir. Deneysel ve laboratuvar yöntemleri zaman alıc1, zahmetli ve büyük ölçekli uygulamalar için zordur. Bazı araştırmalarda ise, ısısal yayım ile toprağın tekstür, hacim ağırlı̆̆ı, su içeriği, organik madde, toprak sıcaklığı vb. gibi kolay belirlenebilen özellikleriyle oluşturulan pedotransfer fonksiyonlar kullanılmıştır (Tombul ve ark., 2004; Dashtaki ve ark., 2010; Guber ve Pachepsky, 2010; Vereecken ve ark.,2010; Ekberli ve ark., 2017; Mengistu ve ark., 2017; Zhang, 2017).

Toprağın 1sı yayınımı karmaşık bir süreç olup, 1sı yayınımına diğer toprak özellikleriyle beraber nem miktarı da önemli düzeyde etki yapmaktadır (Smits et al., 2009; Oladunjoye ve Sanuade,2012; Oladunjoye ve ark., 2013; Rubio, 2013; Busby, 2015; Ekberli ve Gülser, 2016; Rożanski ve Stefaniuk, 2016). Mengistu ve ark. (2017) tarafından, toprağın 1S1 özelliklerine toprak nemi ve sıcaklığın etkisine ait yapılan bir araştırmada, toprak neminin artışına bağlı olarak, 1sısal yayınımın azalan artış gösterdiği saptanmıştır.

$\mathrm{Bu}$ çalışmanın başlıca amaçları; i) temel $1 \mathrm{~s} 1$ iletkenliği denkleminin, toprak yüzeyinde ve herhangi bir derinliğindeki sıcaklık değişimleri arasındaki faz değiş̧imini de içeren sınır koşuluna göre irdelenmesi, ii) denklemin çözümü ile hesaplanan ve ölçülen sıcaklık değerlerinin karşılaştırılması ve iii) toprağın nem içeriğgi ve isısal yayınım katsayısı arasındaki ilişkinin araştırılmasıdır.

\section{Materyal ve Yöntem}

Toprak sıcaklığı ölçümleri Ondokuz Mayıs Üniversitesi Kampus Yerleşim sahası Ziraat Fakültesinin deneme alanında, $2 \mathrm{~m} \times 3 \mathrm{~m}$ parsel büyüklüğünde 12.04-17.06.2005 tarihleri arasında yapılmıştır. Deneme alanı $41^{\circ} 21.86^{\prime}$ Kuzey, 36² $11.41^{\prime}$ Doğu koordinatlarında, deniz seviyesinden $187 \mathrm{~m}$ yükseklikte yer almaktadır.

Toprak sicaklığ $19^{00}, 11^{00}, 13^{00}, 15^{00}, 17^{00}, 19^{00}$ saatlerinde civalı cam termometre ile (Sterling and Jaskson, 1986) 10;20,50 cm toprak derinliğinde, toprak nemliliği ise 3 günde bir aynı derinliklerden alınan örneklerde gravimetrik olarak belirlenmiştir. Toprakların kil, silt ve kum içerikleri hidrometre yöntemine göre (Demiralay, 1993), organik madde (OM) kapsamları modifiye Walkley-Black yaş yakma yöntemine göre saptanmıştır (Kacar, 1994). Toprakların elektriksel iletkenlik değerleri $\left(\mathrm{EC}_{\left.25.4^{\circ} \mathrm{C}\right)}\right)$ 1:1 toprak:su süspansiyonunda, $\mathrm{CaCO}_{3}$ miktarı "Scheibler Kalsimetresi” kullanılarak hacim esasına göre belirlenmiştir (Hızalan ve Ünal, 1966).

Sicaklık dalgalarının toprak derinliği boyunca dağılımının teorik belirlenmesinde ise, temel 1 sı taşınım denkleminin; $\cos \omega t, \sin \omega t$ (burada, $\omega=2 \pi / \mathrm{P}$ açısal frekans, $\mathrm{sn}^{-1} ; \quad \mathrm{t}$-zaman, $\mathrm{sn} ; \mathrm{P}$-periyottur) fonksiyonları ile ifade olunan, toprak yüzeyinde ve $x$ derinliğindeki sıcaklık değişimleri arasındaki faz değişimini de içeren sınır koşuluna göre elde edilen çözümü kullanılmıştır.

\subsection{Istatistiksel analizler}

Standart sapma $(\sigma)$, değişim veya varyasyon katsayısı ( $V K$ ) sırasıyla aşağıdaki (1) ve (2) ifadeleri ile belirlenmiştir:

$$
\begin{gathered}
\sigma=\sqrt{\frac{1}{n} \sum_{i=1}^{n}\left(X_{i}-\bar{X}\right)^{2}} \\
V K=\sqrt{\frac{1}{n} \sum_{i=1}^{n} \frac{\left(X_{i}-\bar{X}\right)^{2}}{\bar{X}}}
\end{gathered}
$$

(burada, $X_{i}$ - ölçülen veya tahmin edilen değerler; $\bar{X}$ - ölçülen veya tahmin edilen değerlerin ortalaması; $n$-ölçülen veya tahmin edilen değerlerin sayıdır). Genel olarak, standart sapmanın küçük olması ortalamadan sapmaların ve riskin az, büyük olması ise ortalamadan sapmaların ve riskin çok olduğunun göstergesidir. Varyasyon veya değişim katsayıları karşılaştırıldığında, değişim katsayısı küçük olan verilerde dağılımın aritmetik ortalama etrafinda daha yoğun dağıldığı anlaşılır.

Hata kareler ortalamasının karekökü (HKOK veya RMSE), mutlak hata (MH veya MAE), maksimum nispi 
hata (MNH veya MRE), ortalama aritmetik hata (OAH ve ya MBE), uygunluk indeksi $(d)$, modelin etkinliği (ME) sırasıyla aşağıdaki (3)-(8) ifadeleri kullanılarak hesaplanmıştır:

$$
H K O K=\sqrt{\frac{1}{m} \sum_{i=1}^{n}\left(x_{i}-y_{i}\right)^{2}}
$$

(burada, $n$-verilerin sayı ve $n<30$ ise $m=n-1$, $n>30$ ise $m=n ; x_{i}-$ hesaplanan; $\quad y_{i}$-ölçülen değerlerdir)

$$
M H=\frac{\sum_{i=1}^{n}\left|x_{i}-y_{i}\right|}{n}
$$

$$
M N H=\underset{i=1,2,3, \ldots n}{\operatorname{mak}}\left(\left|\frac{x_{i}-y_{i}}{y_{i}}\right|\right)
$$

$$
\begin{gathered}
O A H=\sum_{i=1}^{n} \frac{x_{i}-y_{i}}{n} \\
d=1-\frac{\sum_{i=1}^{n}\left(x_{i}-y_{i}\right)^{2}}{\sum_{i=1}^{n}\left(\left|x_{i}-\bar{y}\right|+\left|y_{i}-\bar{y}\right|\right)^{2}}
\end{gathered}
$$

(burada $\bar{x}$ ve $\bar{y}$ sırasıyla hesaplanan ve ölçülen değerlerin ortalamasıdır)

$$
M E=1-\frac{\sum_{i=1}^{n}\left(x_{i}-y_{i}\right)^{2}}{\sum_{i=1}^{n}\left(y_{i}-\bar{y}\right)^{2}}
$$

Hata kareler ortalamasının karekökü (HKOK), tahmin hatalarının standart sapmasını ifade etmektedir. MH ve MNH değerlerinin sıfira yakın olması tercih edilmektedir. OAH'nın sıfira yakın olması, tahmin ve gerçek değerler arasındaki farkın az olduğunu göstermektedir. Pozitif veya negatif bir değer ise, sırasıyla aşırı tahmin veya düşük tahminin bir göstergesidir.

Uygunluk indeksi $(d)$ modelin geçerliliğinin bir göstergesi olup, $d$ 'nin 1'e yakın olması modelin uygulanabilirliğini göstermektedir. Krause ve ark. (2005) tarafindan, deneysel hidrolojik modele yönelik bir araştırmada, ME değerlerinin 1 (mükemmel uyum) ile $-\infty$ arasında değiştiği gösterilmiş; ME'nin sıfirdan küçük olması durumunda ise ölçülen ortalama değerin, hesaplanan değerden daha etkin olduğu belirtilmiştir. $d$ ve ME 'nin analitik ifadelerinin karşılaştıılmasından da görüldüğü gibi, genel olarak $d$ değeri ME'den büyük olmaktadır (Willmott, 1981; Willmott ve
Matsuura, 2005; Krause ve ark., 2005; Willmott ve ark., 2012; Banimahd ve Zand-Parsa, 2013; Usowicz ve ark., 2013; Kumar ve ark., 2015; Wang ve ark., 2016).

\section{Bulgular ve Tartışma}

Araştırmada kullanılan toprağın $0-20 \mathrm{~cm}$ katmanı killi (C), 20-50 cm katmanı ise kumlu-tınlı (SL) olup, tuzluluk problemi bulunmamaktadır. Organik madde içeriği ise orta (0-20 cm katmanında) ile çok az (20-50 $\mathrm{cm}$ katmanda) arasında değişmektedir. Toprakta $\mathrm{CaCO}_{3}$ miktarı az olup, ancak 40-50 $\mathrm{cm}$ katmanında çok az birikme gözükmektedir.

\subsection{Toprak katmanında sicaklik değişiminin teorik olarak belirlenmesi}

Toprağın yüzey sıcaklığı periyodik olarak sürekli değişmekte ve aşağı toprak katmanlarındaki sıcaklık dağılımına etki yapmaktadır. Toprak sıcaklığı zamanın ve derinliğin bir fonksiyonu olup, toprağın 1S1 iletkenliğinin kısmı türevli diferansiyel denklemi ile aşağıdaki gibi ifade edilmektedir:

$$
\frac{\partial T}{\partial t}=a \frac{\partial^{2} T}{\partial x^{2}}(0 \leq \mathrm{x}<\infty, \mathrm{t}>-\infty)
$$

[burada, $T(x, t)$ - toprak sıcaklığı, $t$ - zaman, sn; $a$ isısal yayınım katsayısı, $\mathrm{cm}^{2} \mathrm{sn}^{-1} ; x$ - mesafe, $\left.\mathrm{cm}\right]$.

Yarı sonsuz toprak ortamının $(x \geq 0)$ sinırında $(x=0)$ sıcaklığın $\left(T_{y}\right)$ periyodik değişimi (sınır koşulu) zamanın fonksiyonu olarak, $T_{y}(0, t)=T_{0}+A \cos \omega t \quad$ (10) $\quad$ (burada, $T_{0}$-toprak yüzeyinin ortalama sıcaklı̆ğ, ${ }^{\circ} \mathrm{C} ; A$ - amplitüt, ${ }^{\circ} \mathrm{C}$; $\omega=2 \pi / P$ - açısal frekans, $\mathrm{sn}^{-1} ; P$ - periyottur) biçimindedir. İkinci sınır koşulu olarak, $T \rightarrow T_{0}, \quad x \rightarrow \infty \quad$ (11), yani büyük toprak derinliğinde sıcaklığın ortalama yüzey sıcaklığına yaklaştığ 1 kabul edilir.

(9) denklemi, (10) ve (11) sınır koşullarına göre, değişkenlerine ayırma yöntemiyle çözülür:

$$
T(x, t)=T_{0}+X(x) T^{\prime}(t)
$$

$T^{\prime}(t)$ geçici değişkeninin ancak cos $\omega t$ 'ye eşit olması varsayımında, yüzey altı topraktaki sıcaklık değişimiyle yüzey sıcaklık değişimi aynı olur. Yani $T^{\prime}(t)=\cos \omega t$ durumunda, sicaklığın maksimum ve minimum değerleri tüm derinliklerde aynı zamanda gerçekleşmektedir. Pratikte ise, farklı derinliklerde sıcaklık dağılımı faz değişimi ile oluşmaktadır. Böyle $\mathrm{ki}$, herhangi bir toprak derinliğinde sıcaklık dalgalarının periyoduna uygun olan maksimum sicaklık, yüzey sıcaklığı ile karşılaştırıldığında, gecikmekte ve belirli bir zamandan sonra gerçekleşmektedir. Toprak yüzeyinde ve $x$ derinliğindeki sıcaklık değişimleri arasındaki faz değişiminin göz önüne alınması için, 
$T^{\prime}(t)$ değişkeninin $\cos \omega t$ ve $\sin \omega t$ fonksiyonları ile ifade edilmesi gerekmektedir. Bu durumda, (12) ifadesi aşağıdaki gibi yazılabilir:

$T(x, t)=T_{0}+X_{1}(x) \cos \omega t+X_{2}(x) \sin \omega t$

(13)'den elde edilen

$\frac{\partial T}{\partial t}=-\omega X_{1}(x) \sin \omega t+\omega X_{2}(x) \cos \omega t$;

$\frac{\partial T}{\partial x}=\frac{d X_{1}}{d x} \cos \omega t+\frac{d X_{2}}{d x} \sin \omega t$ ve

$\frac{\partial^{2} T}{\partial x^{2}}=\frac{d^{2} X_{1}}{d x^{2}} \cos \omega t+\frac{d^{2} X_{2}}{d x^{2}} \sin \omega t$ ifadeleri (9)' da

yerine konursa, $X_{1}$ ve $X_{2}$ ' yi belirlemek için

aşağıdaki basit diferansiyel denklemler sistemi elde edilir:

$$
\left\{\begin{array}{l}
-\omega X_{1}=a \frac{d^{2} X_{2}}{d x^{2}} \\
\omega X_{2}=a \frac{d^{2} X_{1}}{d x^{2}}
\end{array}\right.
$$

(14) sisteminden $\quad X_{1}=-\frac{a}{\omega} \frac{d^{2} X_{2}}{d x^{2}} \quad$ olarak, $\frac{d^{4} X_{2}}{d x^{4}}+\frac{\omega^{2}}{a^{2}} X_{2}=0$ (15) elde edilir. Benzer biçimde, $X_{1}$ 'de dördüncü dereceden (15) sabit katsay1lı diferansiyel denklemini sağlamaktadır. (15) diferansiyel denkleminin $\quad \alpha^{4}+\frac{\omega^{2}}{a^{2}}=0 \quad$ karakteristik denkleminin kökleri $\sqrt{\frac{\omega}{2 a}}(1 \pm i)$ ve $-\sqrt{\frac{\omega}{2 a}}(1 \pm i)\left(i^{2}=-1\right) \quad$ olarak, genel çözümü aşağıdaki gibi olur:

$$
\begin{aligned}
& X_{2}=c_{1} e^{\sqrt{\frac{\omega}{2 a}} x} \cos \sqrt{\frac{\omega}{2 a}} x+c_{2} e^{\sqrt{\frac{\omega}{2 a}} x} \sin \sqrt{\frac{\omega}{2 a}} x+c_{3} e^{-\sqrt{\frac{\omega}{2 a}} x} \cos \sqrt{\frac{\omega}{2 a}} x+ \\
& +c_{4} e^{-\sqrt{\frac{\omega}{2 a}} x} \sin \sqrt{\frac{\omega}{2 a}} x
\end{aligned}
$$

Toprak derinliği boyunca sıcaklığın sönme durumuna yaklaşması $(x \rightarrow \infty$ ise $T \rightarrow 0$ ) koşulundan $c_{1}=c_{2}=0$ olarak,

$X_{2}=e^{-\sqrt{\frac{\omega}{2 a}} x}\left(c_{3} \cos \sqrt{\frac{\omega}{2 a}} x+c_{4} \sin \sqrt{\frac{\omega}{2 a}} x\right)$ (17) elde edilir.

$X_{1}$ 'de benzer biçimde ifade edilerek,

$X_{1}=e^{-\sqrt{\frac{\omega}{2 a}} x}\left(c_{5} \cos \sqrt{\frac{\omega}{2 a}} x+c_{6} \sin \sqrt{\frac{\omega}{2 a}} x\right)$ (18) bulunur.

(17) ve (18) ifadeleri (14)'de yerine konursa $c_{3}=-c_{6}$ ve $c_{4}=c_{5}$ olur ve

$$
\begin{aligned}
& X_{2}=e^{-\sqrt{\frac{\omega}{2 a}} x}\left(c_{3} \cos \sqrt{\frac{\omega}{2 a}} x+c_{5} \sin \sqrt{\frac{\omega}{2 a}} x\right) \\
& X_{1}=e^{-\sqrt{\frac{\omega}{2 a}} x}\left(c_{5} \cos \sqrt{\frac{\omega}{2 a}} x-c_{3} \sin \sqrt{\frac{\omega}{2 a}} x\right)
\end{aligned}
$$

(19) ve (20) ifadeleri (13)'de göz önüne alınırsa,

$$
\begin{aligned}
& T(x, t)=T_{0}+e^{-\sqrt{\frac{\omega}{2 a}} x}\left[\left(c_{5} \cos \sqrt{\frac{\omega}{2 a}} x-c_{3} \sin \sqrt{\frac{\omega}{2 a}} x\right) \cos \omega t+\right. \\
& \left.+\left(c_{3} \cos \sqrt{\frac{\omega}{2 a}} x+c_{5} \sin \sqrt{\frac{\omega}{2 a}} x\right) \sin \omega t\right] \quad \text { (21) olur. }
\end{aligned}
$$

(21) ifadesi (10) sınır koşulu ile karşılaştırıldığında $c_{3}=0$ ve $c_{5}=A$. Bu durumda, (21) çözümü

$$
T(x, t)=T_{0}+A e^{-\sqrt{\frac{\omega}{2 a}} x}\left(\cos \omega t \cos \sqrt{\frac{\omega}{2 a}} x+\sin \omega t \sin \sqrt{\frac{\omega}{2 a}} x\right)
$$

veya

$T(x, t)=T_{0}+A e^{-\sqrt{\frac{\omega}{2 a}} x} \cos \left(\omega t-\sqrt{\frac{\omega}{2 a}} x\right)$

(22) olarak

bulunur ve (11) sınır koşulunu sağlamaktadır.

Sıcaklık dalgalarının değişim amplitütü (22) çözümünde $A(x)=\frac{A}{e^{x \sqrt{\frac{\theta}{2 a}}}}$ (23) gibi olup, toprak derinliği boyunca ekspansiyonel olarak azalır. (23) ifadesinden $\ln \frac{A(x)}{A}=-x \sqrt{\frac{\omega}{2 a}}$ olarak, isısal yayınım katsayısının belirlenmesi için $a=\frac{\omega x^{2}}{2 \ln ^{2} \frac{A(x)}{A}} \quad$ (24) elde edilir

(Gülser ve Ekberli, 2002; Ekberli, 2006; Trombotto ve Borzotta, 2009; Correia ve ark., 2012; Ekberli ve Gülser, 2014; Ekberli ve ark., 2015b; Arias-Penas ve ark., 2015; Ekberli ve Sarılar, 2015a; Ekberli ve Dengiz, 2016; Dengiz ve Ekberli, 2017).

\subsection{Toprakta usı oluşumuna etki yapan bazı parametrelerin değişimi}

Araştırma döneminde toprağın $10 \mathrm{~cm}$ katmanında günlük sicaklık, günlük ortalama sicaklık ve günlük maksimum sıcaklık değerleri sırasıyla $12.5-26.8^{\circ} \mathrm{C}$; $13.66-24.85^{\circ} \mathrm{C}$ ve $14.0-26.8^{\circ} \mathrm{C}$ arasında değişmektedir. Genel ortalama sicaklık $\left(T_{0}\right)$ ve genel maksimum 
sicaklık $\left(T_{m a k}\right)$ ise sirasiyla $19.73^{\circ} \mathrm{C}$ ve $21.69^{\circ} \mathrm{C}$ olarak saptanmıştır. $A=T_{m a k}-T_{0}$ ifadesiyle hesaplanan günlük amplitütler $0.34-2.73^{\circ} \mathrm{C}$ arasında değişmekte ve $1.96^{\circ} \mathrm{C}$ genel ortalama değerine sahip olmaktadır. (24) ifadesiyle hesaplanan günlük ısısal yayınım katsayıları

(a) $0.61 \cdot 10^{-7}-5.68 \cdot 10^{-7} \mathrm{~m}^{2} \mathrm{sn}^{-1}$ arasinda olup, $2.97 \cdot 10^{-7}$ $\mathrm{m}^{2} \mathrm{sn}^{-1}$ ortalama değere sahiptir. Ölçülen sicaklık dağılımının standart sapması 3.57 , değişim katsayısı ise 0.18 olup, sıcaklık dağılımının homojen olduğu gözükmektedir. Toprak nemi ise \% 24.7-40.8 arasinda değişmektedir.

Toprağın $20 \mathrm{~cm}$ katmanında günlük sıcaklık, günlük ortalama sicaklı ve günlük maksimum sicaklık değerleri sirasıyla $12.0-25.4^{\circ} \mathrm{C} ; 13.36-24.25^{\circ} \mathrm{C}$ ve 14.0 $25.4^{\circ} \mathrm{C}$ arasında; $T_{0}$ ve $T_{\text {mak }}$ değerleri ise sirasiyla $18.42^{\circ} \mathrm{C}$ ve $19.61^{\circ} \mathrm{C}$ olarak belirlenmiştir. Günlük ve ortalama amplitüt değerleri; günlük 1sısal yayınım katsayıları ve ortalaması sirasıyla $0.45-2.75^{\circ} \mathrm{C} ; 1.19^{\circ} \mathrm{C}$; $0.31 \cdot 10^{-6}-9.29 \cdot 10^{-6} \mathrm{~m}^{2} \mathrm{sn}^{-1} ; 4.02 \cdot 10^{-6} \mathrm{~m}^{2} \mathrm{sn}^{-1}$ olarak hesaplanmıştır. Sıcaklık dağılımının standart sapması 3.48, değişim katsayısı ise 0.19 olup, sıcaklık dağılımı homojen olmaktadır. Topraktaki nem miktarı ise \% 28.2-36.6 arasında saptanmıştır.

Araştırma toprağının $50 \mathrm{~cm}$ 'lik katmanında günlük sicaklık $10.5-22.4^{\circ} \mathrm{C}$; günlük ortalama sicaklık 11.47 $21.77^{\circ} \mathrm{C}$; günlük maksimum sicaklık ise $12.4-22.4{ }^{\circ} \mathrm{C}$ arasında değişmektedir. $T_{0}$ ve $T_{m a k}$ değerleri ise sırasıyla $17.0^{\circ} \mathrm{C}$ ve $17.9^{\circ} \mathrm{C}$ olarak saptanmıştır. Günlük amplitütler $0.15-2.05^{\circ} \mathrm{C}$ arasında değişmekte, ortalama değer ise $0.9^{\circ} \mathrm{C}$ olmaktadır. Günlük isısal yayınım katsayılar1 $3.43 \cdot 10^{-7}-9.49 \cdot 10^{-5} \mathrm{~m}^{2} \mathrm{sn}^{-1}$, ortalamasi ise $2.51 \cdot 10^{-5} \mathrm{~m}^{2} \mathrm{sn}^{-1}$ olarak hesaplanmıştır. Sicaklık dağılımının standart sapması 3.11, değişim katsayısı ise 0.18 olup, sıcaklık dağılımı homojendir. Toprak nemi \% 24.4-39.3 arasında belirlenmiştir.

Toprağın 10 ve $20 \mathrm{~cm}$ katmanları ile karşılaştırıldığında, $50 \mathrm{~cm}$ katmanda sıcaklık değişimi az olduğu için, ortalama amplitüt değeri düşük; isısal yayınım katsayısı ise büyük olmaktadır. Genel olarak, 1sısal parametrelerin değişimine iklim faktörü önemli düzeyde etki yapmakta ve sicaklı̆̆ın tahminini zorlaştırmaktadır. Araştırma toprağı katmanlarında, sıcaklık dağılımlarının homojen olması, amplitüt değerlerinin yüksek farklılık göstermemesine neden olan faktörlerdendir.

\subsection{Deneysel ve isl iletkenliği denkleminin çözümüne bağlı olarak belirlenen toprak sicaklıklarının karşılaş̧tırılması}

Toprak katmanının deneysel olarak belirlenen ortalama sıcaklığı ( $T_{0}$ ), amplitütü ( $A$ ) ve (24) ifadesine

göre $\quad\left(\omega=2 \pi / \mathrm{P}=\frac{6.28}{86400 \mathrm{sn}} \approx 0.0000727 \mathrm{sn}^{-1}\right.$ olarak $)$

hesaplanan 1sısal yayınım ( $a$ ) katsayısı göz önüne alınarak, (22) çözümü ile $10 \mathrm{~cm}, 20 \mathrm{~cm}$ ve $50 \mathrm{~cm}$ katmanları için elde edilen teorik toprak sıcaklıklarının ve ölçülen toprak sıcaklıklarının dağılımı Şekil 1'de verilmiştir.
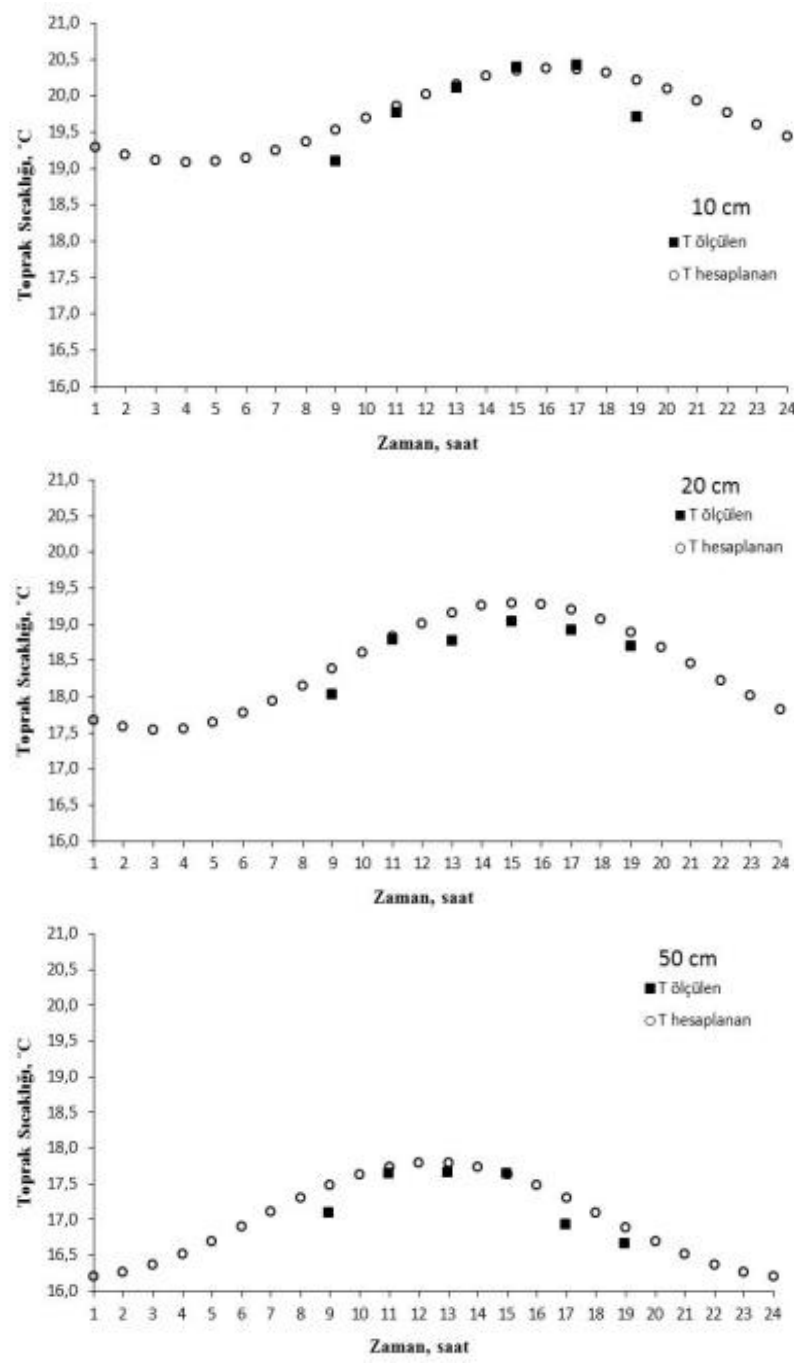

Şekil 1. Toprağın $10 \mathrm{~cm}, 20 \mathrm{~cm}$ ve $50 \mathrm{~cm}$ derinliklerinde hesaplanan ve ölçülen sıcaklık değerleri

Şekil 1'den görüldüğg̈ gibi, sıcaklık değişimi $10 \mathrm{~cm}$ ve $20 \mathrm{~cm}$ katmanlarında, $50 \mathrm{~cm}$ katmanından daha fazla olmaktadır. $50 \mathrm{~cm}$ katmanında ortalama yüzey katman sıcaklığının ve amplitüt değerlerinin düşük, isısal yayınım katsayısının ise yüksek olması, diğer toprak özellikleriyle beraber, sıcaklık değişimin az olmasına etki yapan önemli faktörlerdir.

Toprağın 1sı iletkenliği denkleminin (22) çözümünün uygulanabilirliğinin kontrolü için, hesaplanan ve ölçülen toprak sıcaklıklarının karşılaştırılmasına ait istatistiksel göstergeler Çizelge 1'de verilmiştir. 
Çizelge 1. Modelin geçerliliğine ait istatistiksel göstericiler

\begin{tabular}{|c|c|c|c|c|c|c|c|c|c|c|}
\hline \multirow{2}{*}{$\begin{array}{c}\text { Derinlik, } \\
\mathrm{cm}\end{array}$} & \multicolumn{2}{|c|}{$\sigma,{ }^{\circ} \mathrm{C}$} & \multicolumn{2}{|r|}{ VK } & \multirow{2}{*}{ 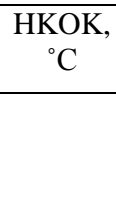 } & \multirow{2}{*}{$\begin{array}{c}\mathrm{MH}, \\
{ }^{\circ} \mathrm{C}\end{array}$} & \multirow[t]{2}{*}{$\mathrm{MNH}$} & \multirow{2}{*}{$\begin{array}{l}\mathrm{OAH}, \\
{ }^{\circ} \mathrm{C}\end{array}$} & \multirow[t]{2}{*}{$\mathrm{d}$} & \multirow[t]{2}{*}{$\mathrm{ME}$} \\
\hline & $\begin{array}{r}\text { *Ölçülen } \\
\text { değerlere } \\
\text { göre }\end{array}$ & $\begin{array}{c}\text { Hesaplanan } \\
\text { değerlere } \\
\text { göre }\end{array}$ & $\begin{array}{r}\text { *Ölçülen } \\
\text { değerlere } \\
\text { göre }\end{array}$ & $\begin{array}{c}\text { Hesaplanan } \\
\text { değerlere } \\
\text { göre }\end{array}$ & & & & & & \\
\hline 10 & 0.500 & 0.327 & 0.025 & 0.016 & 0.286 & 0.200 & 0.027 & 0.180 & 0.868 & 0.607 \\
\hline 20 & 0.352 & 0.337 & 0.019 & 0.018 & 0.291 & 0.268 & 0.022 & 0.268 & 0.816 & 0.181 \\
\hline 50 & 0.434 & 0.334 & 0.025 & 0.019 & 0.246 & 0.205 & 0.023 & 0.198 & 0.889 & 0.617 \\
\hline
\end{tabular}

*Karşılaştırılmada kullanılan ölçülen değerler

Çizelge 1'den görüldüğü gibi, toprağın 10,20 ve $50 \mathrm{~cm}$ katmanlarında, modelin geçerliliğinin kontrol edilmesinde kullanılan ölçülen ve hesaplanan değerlerin standart sapması küçük, dolayısıyla riskin derecesi az olmaktadır. Her üç katmanda da, değişim katsayılarının değerleri küçük (\% 1.6-2.5) olup, ölçülen ve hesaplanan sicaklık değerleri ortalama etrafinda daha yoğun dağılıma sahiptir. Tahmin hatalarının standart sapması, mutlak hata, maksimum nispi hata, ortalama aritmetik hata değerleri düşük olup, tahmin ve gerçek değerler arasındaki farkın az, dolayısıyla toprak sicaklığının günlük değişiminde modelin güvenirlik derecesinin yüksek olduğunu göstermektedir. d ve ME değerleri de uygulanabilirlik sınırları dahilinde olmaktadır. Toprağın $10 \mathrm{~cm}$ ve $50 \mathrm{~cm}$ derinliklerindeki ME değerleri ile karşılaştırıldığında, $20 \mathrm{~cm}$ toprak derinliğindeki değerin fazla düşük olması $x_{i}-y_{i}$ ve $y_{i}-\bar{y}$ değerlerinin farklılık $\quad\left[\left(x_{i}-y_{i}\right)>>\left(y_{i}-\bar{y}\right)\right]$ göstermesinden kaynaklanabilir.

\subsection{Toprak neminin isısal yayınım katsayısina etkisi}

Toprağın 10,20 ve $50 \mathrm{~cm}$ katmanlarında nemin ısısal yayınım katsayısının değişimine etkisi Şekil 2'de verilmiştir.

Her üç katmanda nemin artışı ile beraber, ısısal yayınım katsayısı da artış göstermekte, nemin sonraki artı̧̧ında $(\mathrm{W}>\approx \% 30-32)$ ise 1sısal yayınımın azalma süreci başlamaktadır. Değişim süreci düzenli olmamakta, nem ve ısısal yayınım ilişkisi yaklaşık parabolik biçimde gerçekleşmektedir. Toprağın 10, 20, $50 \mathrm{~cm}$ derinliklerinde, nem miktarı ile 1sisal yayınım ilişkilerinin belirleme katsayısı sırasıyla $0.77 ; 0.41$ ve 0.54 olarak belirlenmiştir. Toprağın 10 ve $50 \mathrm{~cm}$ derinliklerinde, $20 \mathrm{~cm}$ derinlikle karşılaștırıldığında, sıcaklığın amplitüt değişimlerinin daha çabuk sabitleşmesi belirleme katsayılarının yüksek olmasına neden olabilir.

Toprakların ısısal yayınım katsayısı, 1sı iletkenliği ile doğrusal, 1sı kapasitesi ile ters orantıll, 1sı iletkenliği ve 1S1 kapasitesine etki yapan faktörlere bağlı olmakla beraber kendine özgü bir özelliğe sahiptir. Çudnovski (1976) tarafından yapılan bir araştırmada, topraktaki nemin değișimine uygun olarak isısal yayınımın da maksimum kuralı ile değişmekte olduğu gösterilmiştir.
Kurtener ve Çudnovski (1979) ve Voronin (1986)'e göre ise, isısal yayınım toprağın pulluk tabakası dışındaki diğer horizonlarda nem içeriği tarla kapasitesindeyken maksimum değerler almakta, doygunluk noktasında ise daha düşük değerlere ulaşmaktadır.
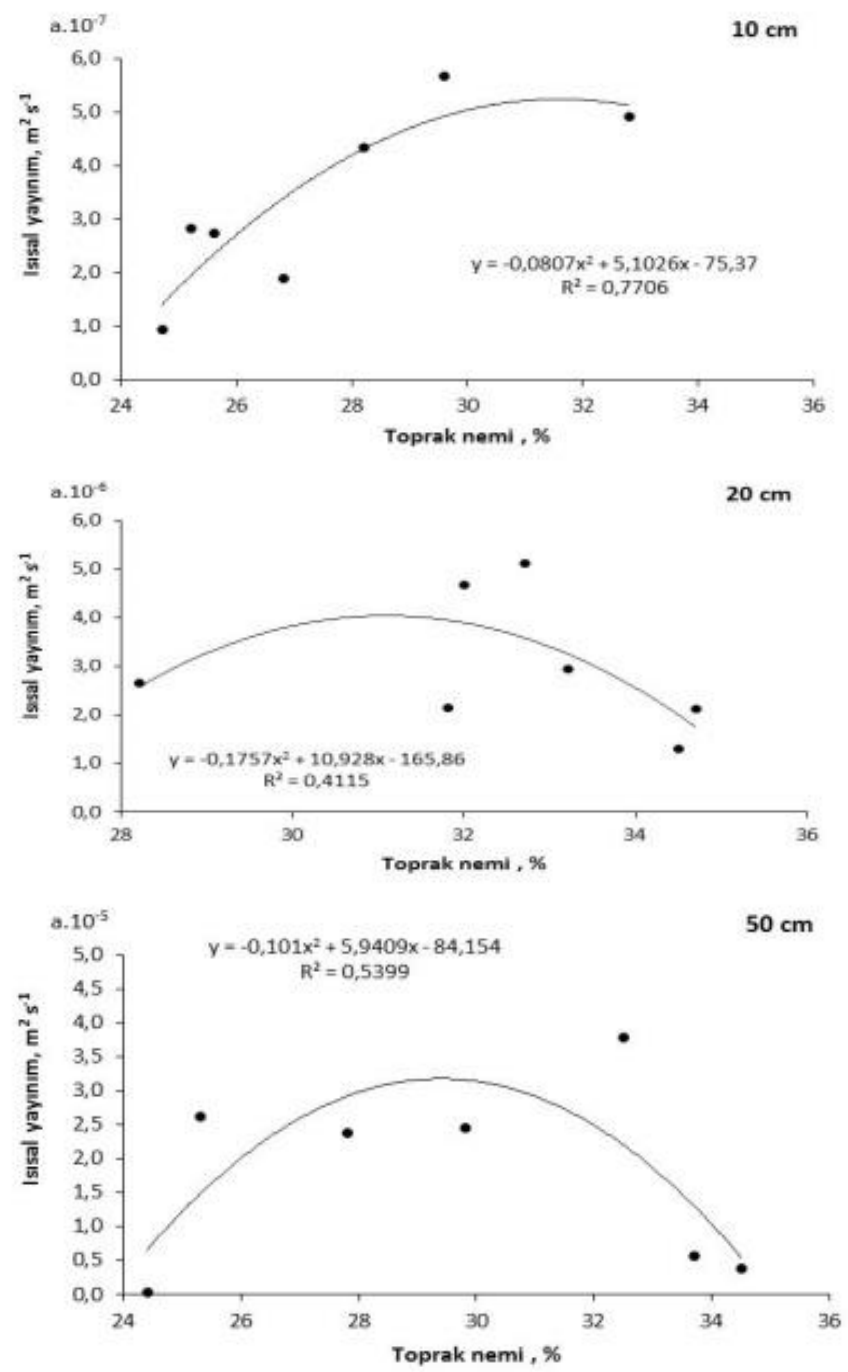

Şekil 2. Isısal yayınım katsayısının toprak nemine bağlı olarak değişimi 


\section{Sonuç ve Öneriler}

Toprak yüzeyinde ve aşağı katmanlarda sıcaklık dalgalarının maksimum veya minimum değer alması, zamana bağlı olarak sıcaklık amplitütünün değişimi, maksimum veya minimum sıcaklığın aşağı katmanlardaki sönme derinliği ve gecikme zamanı, sıcaklık dalgalarının faz değişimine önemli düzeyde bağlı olmaktadır. $\mathrm{Bu}$ nedenle, toprağın temel isı iletkenliği denkleminin, toprak yüzeyinde ve herhangi bir derinlikteki sıcaklık değişimleri arasındaki faz değişimini de içeren sınır koşuluna göre çözümün incelenmesi gerekmektedir. Isı iletkenliği denkleminin çözümüne bağlı olarak hesaplanan ve ölçülen günlük sıcaklık değerlerinin karşılaştırılması, denklemin

\section{Kaynaklar}

Arias-Penas, D., Castro-Garcia, M.P., Rey-Ronco, M.A., Alonso-Sanchez, T., 2015. Determining the thermal diffusivity of the ground based on subsoil temperatures. Preliminary results of an experimental geothermalborehole study Q-THERMIE-UNIOVI. Geothermics, 54: 35-42.

Banimahd, S.A., Zand-Parsa, Sh., 2013. Simulation of evaporation, coupled liquid water, water vapor and heat transport through the soil medium. Agricultural Water Management, 130: 168- 177.

Braud, I., Dantas-Antonino, A.C., Vauclin, M., Thony, J.L., Ruelle, P., 1995. A simple soil plant atmosphere transfer model (SiSPAT). Development and field verification. Journal of Hydrology, 166 (34): $213-250$

Busby, J., 2015. Determination of thermal properties for horizontal ground collector loops. British Geological Survey, Nottingham, UK.

Camillo, P.J., Gurney, R.J., Schmugge, T.J., 1983. A soil and atmospheric boundary layer model for evapotranspiration and soil moisture studies. Water Resources Research, 19: 371-380.

Chacko, P.T., Renuka, G., 2002. Temperature mapping, thermal diffusivity and subsoil heat flux at Kariavattom of Kerala. Proceedings of the Indian Academy Science (Journal of Earth System Scince)., 111(1): 79-85.

Chen, S.T., Huang, Y., Zou, J.W., Shi, Y.S., 2013. Mean residence time of global topsoil organic carbon depends on temperature, precipitation and soil nitrogen. Global and Planetary Change, 100: 99-108.

Chudnovskii, A.F., 1976. Thermophysics of soils (in Russian). Press Nauka, Moscow, 352 p.

Correia, A., Vieira, G., Ramos, M., 2012. Thermal conductivity and thermal diffusivity of cores from a 26 meter deep borehole drilled in Livingston Island, Maritime Antarctic. Geomorphology, 155(156): 711.

Dashtaki, S.G., Homaee, M., Khodaverdiloo, H., 2010. çözümünün günlük sıcaklık değişimini iyi tahmin ettiğini göstermektedir. Dolayısıyla, 1sı iletkenliği denkleminin çözümünün günlük sicaklık değişiminin tahminin de kullanılması gerekmektedir.

İklim koşullarının, toprak yüzeyinde ve aşağı katmanlarda ortalama sıcaklığın, amplitütütün değişimi nedeniyle, denklemin çözümünün birbirini takip eden birden fazla günler için uygulanabilirliğini ifade etmek zordur. Tahmin sürecine önemli düzeyde etki yapan ısısal yayınım katsayısı, toprağın aşağı derinliklerinde artmakta, neme bağlı olarak ise azalan artış göstermektedir. Isısal yayınım ve nem arasındaki ilişkinin parabolik fonksiyonla ifadesi mümkün gözükmektedir.

Derivation and validation of pedotransfer functions for estimating soil water retention curve using a variety of soil data. Soil Use and Management, 26 (1): 68-74.

Davidson, E.A., Janssens, I.A., 2006. Temperature sensitivity of soil carbon decomposition and feedbacks to climate change. Nature, 440: 165-173.

Demiralay, İ., 1993. Toprak fiziksel analiz yöntemleri. Atatürk Üniversitesi Ziraat Fakültesi Yayınları, Erzurum, 111-120.

Dengiz, O., Ekberli,I., 2017. Bazı vertisol alt grup topraklarının fizikokimyasal ve 1sısal özelliklerinin incelenmesi. Akademik Ziraat Dergisi, 6(1): 45-52.

de Vries, D.A., 1963. Thermal properties of soils. In: W.R. van Wijk (Editor), Physics of Plant Environment. North Holland, Amsterdam, pp. 210235.

Ekberli, I, 2006. Determination of initial unconditional solution of heat conductivity equation for evaluation of temperature variance in finite soil layer. Journal of Applied Sciences, 6(7): 1520-1526.

Ekberli, İ., Dengiz, O., 2016. Bazı inceptisol ve entisol alt grup topraklarının fizikokimyasal özellikleriyle 1sısal yayınım katsayısı arasındaki regresyon ilişkilerin belirlenmesi. Toprak Su Dergisi, 5(2): 110.

Ekberli,I., Gülser, C., 2014. Estımatıon of soil temperature by heat conductivity equation. Vestnik Bashkir State Agrarian University (Вестник Башкирского Государственного Аграрного Университета), 2 (30): 12-15.

Ekberli, İ., Gülser, C., 2015. İki boyutlu 1sı iletkenliği denklemine bağlı olarak toprak sıcaklığının matematiksel modellenmesi Anadolu Tarım Bilim. Dergisi, 30 (3): 287-291.

Ekberli, İ., Gülser C., 2016. Toprağın ısısal yayınımının fonksiyonel değișimi ve toprak sıcaklığına etkisi. Anadolu Tarım Bilimleri Dergisi, 31 (2): 294-300.

Ekberli, İ., Gülser, C., Mamedov, A., 2015a. Toprakta bir boyutlu 1s1 iletkenlik genkleminin incelenmesinde benzerlik teorisinin uygulanması. Süleyman Demirel Üniversitesi Ziraat Fakültesi Dergisi, 10(2): 69-79.

Ekberli, İ., Gülser, C., Özdemir, N., 2015b. Toprakta 1s1 
iletkenliğine etki yapan isısal parametrelerin teorik incelemesi. Anadolu Tarım Bilimleri Dergisi, 30(3): 300-306.

Ekberli, İ., Gülser, C., Özdemir, N., 2017. Farklı toprak derinliklerindeki sıcaklığın tahmininde parabolik fonksiyonun kullanımı. Toprak Bilimi ve Bitki Besleme Dergisi, 5(1): 34- 38.

Ekberli, İ., Sarılar, Y., 2014. Investigating soil temperature variability and thermal diffusivity in grass cowered and shaded areas by trees. Pocvovedeniye i Agrohimiya, Almatı (Почвоведение и агрохимия, Алматы, № 4, 2014), 4: 17-30.

Ekberli, İ., Sarılar, Y., 2015a. Toprak sıcaklığı ve 1sısal yayınımın belirlenmesi. AnadoluTarım Bilimleri Dergisi, 30(1): 74-85.

Ekberli, İ., Sarılar, Y., 2015b. Toprak sıcaklığının profil boyunca sönme derinliğinin ve gecikme zamanının belirlenmesi. Ege Üniversitesi Ziraat Fakültesinin Dergisi, 52 (2): 219-225.

Elias, E.A, Cichota, R., Torriani, H.H., De Jong van Lier, Q., (2004). Analytical soil-temperature model correction for temporal variation of daily amplitude. Soil Science Society America Journal, 68: 784-788.

Farouki, O.T., 1981. The thermal properties of soils in cold regions. Cold Regions Science and Technology, 5(1), 67-75.

Guber, A.K., Pachepsky, Y.A., 2010. Multimodeling with pedotransfer functions: documentation and user manual for PTF calculator (CalcPTF), Version 2.0., USDA-ARS, USA.

Gülser, C., Ekberli, I., 2004. A comparison of estimated and measured diurnal soil temperature through a clay soil depth. Journal of Applied Sciences, 4(3): 418-423.

Gülser, C., Ekberli, İ., 2002. Toprak sıcaklığının profil boyunca değişimi. Ondokuz Mayıs Üniversitesi Ziraat Fakültesinin Dergisi, 17(3): 43-47.

Hızalan, E. ve Ünal, H., 1966. Toprakta önemli kimyasal analizler. Ankara Üniversitesi Ziraat Fakültesi Yayınları, 278s.

Johansen, D., 1975. Thermal property of soils. Ph.D. Thesis, Trondheim University.

Kacar, B., 1994. Bitki ve toprağın kimyasal analizleri:III. Ankara Üniversitesi Ziraat Fakültesi Eğitim, Araştırma ve Geliştirme Vakfı Yayınları. No:3, 89-98.

Knight, J.H., Minasny, B., McBratney, A.B., Koen, T.B., Murphy, B.W., 2018. Soil temperature increase in eastern Australia for the past 50 years. Geoderma, 313: 241-249.

Kumar, P., Sarangi, A., Singh, D.K., Parihar, S.S., Sahoo, R.N., 2015. Simulation of salt dynamics in the root zone and yield of wheat cropunder irrigated saline regimes using SWAP model. Agricultural Water Management, 148: 72-83.

Krause, P., Boyle, D.P., Base, F.B., 2005. Comparison of different efficiency criteria for hydrological model assessment. Advances in Geosciences, 5: 89-
97.

Kurtener, D.A., Chudnovskii, A.F., 1979. Agrometeorological basics of the thermal amelioration of soils (in Russian). Press Gidrometeoizdat, Leningrad, $231 \mathrm{p}$.

Lei, S., Daniels, J.L., Bian, Z., Wainaina, N., 2011. Improved soil temperature modeling Environmental Earth Sciences, 62:1123-1130.

Lettau, H.H. 1954. Improved models of thermal diffusion in the soil. Transactions of the American Geophysical Union, 35: 121-132.

Liang, H., Hu, K., Qin, W., Zuo, Q., Zhang, Y., 2017. Modelling the effect of mulching on soil heat transfer, watermovement and crop growth for ground cover rice production system. Field Crops Research, 201: 97-107.

Mengistu, A.G., van Rensburg, 1.D., Mavimbela, S.S.W., 2017. The effect of soil water and temperature on thermal properties of two soils developed from aeolian sands in South Africa. Catena, 158: 184-193.

Milly, P.C.D., 1986. An event-based simulation model of moisture and energy fluxes at a bare soil surface. Water Resources Research, 22(12): 1680-1692.

Novak, M.D. and Black, T.A., 1985. Theoretical Determination of the surface energy balanc and thermal regimes of bare soils. Boundary-Layer Meteorology, 33(4): 313-333.

Oladunjoye, M.A., Sanuade, O.A., 2012. Thermal diffusivity, thermal effusivity and specific heat of soils in Olorunsogo Powerplant, southwestern Nigeria. IJRRAS., 13 (2): 502-521.

Oladunjoye, M.A., Sanuade, O.A., Olaojo, A.A., 2013. Variability of soil thermal properties of a seasonally cultivated agricultural teaching and research farm, university of Ibadan, south-western Nigeria. GJSFRD., 13 (8): 41-64.

Passerat de Silans, A.M.B., Bruckler, L., Thony, J.L., Vanclin, M., 1989. Numerical modeling of coupledheat and water flows during drying in a stratified bare soil. Comparison with field observations. Journal of Hydrology, 105: 109-138.

Passerat de Silans, A.M. B., Monteny, B.A., Lhomme, J.P., 1996. Apparent soil thermal diffusivity, a case study: HAPEX-Sahel experiment. Agricultural and Forest Meteorology, 81: 201-216.

Rafique, R., Kumar, S., Luo, Y.Q., Xu, X.L., Li, D.J., Zhang,W., Asam, Z.U., 2014. Estimation of greenhouse gases ( $\mathrm{N} 2 \mathrm{O}, \mathrm{CH} 4$ and $\mathrm{CO} 2)$ from no-till cropland under increased temperature and altered precipitation regime: a DAYCENT model approach. Global and Planetary Change, 118: 106-114.

Rozanski, A., Stefaniuk, D., 2016. Prediction of soil solid thermal conductivity from soil separates and organic matter content: computational micromechanics approach. European Journal of Soil Science, 67 (5): 551-563.

Rubio, C.M., 2013. A laboratory procedure to determine the thermal properties of silt loam soils based on 
ASTM D 5334. AEES., 1 (4): 45-48.

Smits, K.M., Sakaki, T., Limsuwat, A., Illangasekare, T.H., 2009. Determination of the thermal conductivity of sands under varying moisture, drainage/wetting, and porosity conditionsapplications in near-surface soil moisture distribution analysis. In: AGU Hydrology Days 2009, Goldon, USA, pp. 57-65.

Sterling, A.T. and R.D. Jackson, 1986. Temperature. In: Klute, A. (Ed.), Methods of Soil Analysis Part 1. Physical and Mineralogical Methods. Agronomy Monograph No. 9, ASA, SSSA, Madison WI.

Tombul, M., Akyürek, Z., Sorman, A.Ü., 2004. Research note: determination of soil hydraulic properties using pedotransfer functions in a semiarid basin. Turkey. Hydrology Earth System Sciences, 8 (6): 1200-1209.

Trombotto, D., Borzotta, E., 2009. Indicators of present global warming through changes in active layerthickness, estimation of thermal diffusivity and geomorphological observations in the Morenas Coloradas rockglacier, Central Andes of Mendoza, Argentina. Cold Regions Science and Technology, 55: 321-330.

Usowicz, B., Lipiec, J., Usowicz, J.B., Marczewski, W., 2013. Effects of aggregate size on soil thermal conductivity: Comparison of measured and modelpredicted data. International Journal of Heat and Mass Transfer, 57: 536-541.

Van Wijk, W.R. (Editor), 1963. Physics of Plant Environment. First edition. North Holland, Amsterdam.

Vereecken, H., Weynants, M., Javaux, M., Pachepsky,
Y., Schaap, M.G., van Genuchten, M.T., 2010. Using pedotransfer functions to estimate the van Genuchten-Mualem soil hydraulic properties: a review. Vadose Zone Journal, 9(4): 795-820.

Voronin, A.D., 1986. Fundamentals of soil physics (in Russian). Press Moscow State University, Moscow, $244 \mathrm{p}$.

Wang, L., Li, X., Chen, Y., Yang, K., Chen, D., Zhou, J., Liu, W., Qi, J., Huang, J., 2016. Validation of the global land data assimilation system based onmeasurements of soil temperature profiles. Agricultural and Forest Meteorology, 218-219: 288-297.

Willmott, C.J., 1981. On the validation of models. Physical Geography, 2: 184-194.

Willmott, C.J., Matsuura, K., 2005. Advantages of the mean absolute error (MAE) over the root mean square error (RMSE) in assessing average model performance. Climate Research 30: 79-82.

Willmott, C. J., Robeson, S.M., Matsuura, K., 2012. Short Communication. A refined index of model performance. International Journal of Climatology, 32: 2088-2094.

Yvon-Durocher, G., Allen, A.P., Bastviken, D., Conrad, R., Gudasz, C., St-Pierre, A., Thanh-Duc, N., del Giorgio, P.A., 2014. Methane fluxes show consistent temperature dependence across microbial to ecosystem scales. Nature, 507 (7493): 488-495.

Zhang, T., Cai, G., Liu, S., Puppala, A.J., 2017. Investigation on thermal characteristics and prediction models of soils. International Journal of Heat and Mass Transfer, 106: 1074-1086. 